\title{
tratamento das superfícies arquitetônicas como problema teórico da restauração
}

Beatriz Mugayar Kühl*

Depto. de História da Faculdade de Arquitetura

e Urbanismo da Universidade de São Paulo
*A autora conta atualmente com uma Bolsa de Auxílio à Pesquisa da Fapesp.

RESUMO: $\bigcirc$ artigo aborda a questão das superfícies arquitetônicas e sua relação com a teoria de restauração. São examinadas com esse intuito, em linhas gerais, as transformações por que passaram as teorias de restauro. Analisam-se também as tendências contemporâneas, com o intuito de averiguar os princípios gerais que deveriam guiar as intervenções. Verificase então o que ocorre na prática de intervenções em superfícies arquitetônicas, notando-se que há uma dissociação entre teoria e prática. Neste texto, procura-se enfatizar a relevância da reflexão teórica para enfrentar os problemas em toda a sua complexidade e como meio eficiente de preservar os aspectos materiais, históricos, formais e simbólicos dos monumentos. PALAVRAS-CHAVE: Superfícies arquitetônicas. Teoria da restauração. Monumentos históricos.

ABSTRACT: The article deals with the question of architectural surfaces and their relation with restoration theories. The historical transformations undergone by restoration theories are examined in broad lines. The contemporary tendencies of restoration theories are also analyzed in order to verify the principles that should guide the interventions. The dissociation between theory and practice arises through the analysis of the practice of interventions in architectural surfaces. In this text, the author seeks to place an emphasis on the relevance of reflection on theoretical principles in order to face problems in their full intricacy, and as an efficient means of preserving the material, historic, formal and symbolic values of monuments.

KEYWORDS: Architectural Surfaces. Restoration Theory. Historic Monuments.

Uma questão de primordial importância a ser considerada nas intervenções em edifícios de interesse histórico é o tratamento das superfícies. A abordagem desse problema depende da proposta de restauração como um todo, resultante de análises pormenorizadas do edifício ou conjunto de edifícios e do ambiente em que estão inseridos. Todas as decisões relativas às ações a 
1. Convém enfatizar que a expressão monumento histórico está sendo utilizada,neste texto,em sua acepção primeira e não com o caráter de obra grandiosa e isolada. Devese recordar que monumento é um instrumento da memória, destinado à rememoração de fatos, in divíduos ou crenças, es tando presente em todos os povos e culturas. Monumento histórico, por sua vez, é uma criação da cultura ocidental, referindo-se a um artefato que, com o tempo, por seus valores históricos, artísticos ou simbólicos, adquiriu significação cultural, tenha sido ele feito ou não com intenções me moriais e seja ele ou não uma obra "grandiosa", como tão bem exposto por Riegl. Cf. RIEGL, 1984.

2. Para a análise das transformações da noção de restauro ao longo do tempo até os debates con temporâneos, cf. CARBONARA, 1997; CHOAY, 2001; JOKILEHTO, 1999. serem desenvolvidas, incluindo-se o tratamento de superfícies, deveriam, de forma articulada, resultar dessa análise, seguindo os princípios basilares que regem a restauração. $O$ tratamento de superfícies deve ser encarado dentro desse processo e deve ser reconhecido com o status de um verdadeiro problema da restauração, ou seja, problema também histórico-crítico, e não apenas decisão baseada unicamente em critérios técnicos e, muito menos, como simples questão de gosto ou de moda.

A restauração não é mero processo técnico, apesar da relevância fundamental do emprego de técnicas adequadas. Há pelo menos um século, a preservação de bens culturais se afirmou como campo disciplinar autônomo, afastando-se do empirismo que caracterizava muitos dos procedimentos até então e vinculando a restauração a um processo histórico-crítico.

Esse processo teve um lento maturar no decorrer dos séculos. A preservação dos monumentos históricos' deixou, de modo paulatino, de ser uma ação ditada essencialmente por razões de cunho prático e se firmou como ação cultural, em especial a partir do fim do século XVIII'2. No entanto, noções que floresceram a partir do Renascimento amadureceram de forma gradual no período que se estende dos séculos XV ao XVIII e foram conjugadas na formação das teorias de restauro: o respeito pela matéria original; a idéia de reversibilidade e distinguibilidade da intervenção; a importância de documentação, extensa e precisa, da obra antes, durante e depois da intervenção e do emprego de uma metodologia científica, preceitos sistematizados sobretudo a partir dos trabalhos de Johann Joachim Winckelmann; o interesse por aspectos conservativos e de mínima intervenção, destacando-se os trabalhos de Giovan Battista Piranesi, que deu continuidade aos exercícios de levantamento pormenorizado, análise e reconstituição hipotética de edifícios antigos, também como modo de fundamentar a criação contemporânea sua, que se desenvolviam desde o Renascimento lesse tipo de instrumental, iá bastante amadurecido, foi fundamental nos trabalhos de restauração); a noção de ruptura entre passado e presente.

Vários fatores se somaram ao processo de alteração da relação de uma dada cultura com seu próprio passado, a exemplo do lluminismo, das profundas e aceleradas mudanças ocasionadas pela Revolução Industrial, a princípio na Grã-Bretanha, e das reações às destruições maciças posteriores à Revolução Francesa. Esses e outros fatores acentuaram a noção de ruptura entre passado e presente, fazendo com que aos poucos, e principalmente a partir do fim do século XIX, percebesse-se que o momento de intervenção em uma obra era distinto daquele de sua criação e que, portanto, a forma de atuar deveria evidenciar essa diferença, sendo respeitosa em relação às várias fases por que passou o monumento. Já a partir da segunda metade do século XVIII, a restauração se afastou cada vez mais das ações ditadas por razões pragmáticas e começou a assumir uma conotação fundamentalmente cultural, com maior rigor e método nos procedimentos, conseqüência de séculos de experimentações e também da difusão dos ideais do lluminismo. As ações passaram a ser, paulatinamente, alicerçadas no conhecimento histórico e em análises formais, por sua vez 
balizadas pela historiografia da arte e pelas teorias estéticas fundamentadas na crítica, a exemplo daquelas formuladas por Kant.

Personagem de grande importância nesse contexto foi Quatremère de Quincy. Figura de proa no cenário cultural do fim do século XVIII e início do século XIX, foi debatedor ardoroso das questões ligadas ao futuro da produção artística, sendo profundamente marcado pelas teorias de Winckelmann. Os escritos de Quatremère de Quincy sobre a preservação de bens culturais possuem grande interesse, levantando algumas questões relevantes. Suas formulações deixam de ser os enunciados sucintos e pragmáticos que associavam a restauração à repristinação, assim como ocorrera em definições anteriores sobre o tema - a exemplo daquelas que comparecem no tratado de D'Aviler ${ }^{3}$ e na Enciclopédia Diderot-D'Alembert (que retoma literalmente as colocações de D'Aviler) - e passam a ter uma elaboração mais complexa, não livre de certas contradições. Quatremère de Quincy alarga o debate sobre várias questões, que permanecem essenciais para a reflexão atual sobre a preservação de bens culturais, tais como: a importância de fazer integrações; a necessidade de manutenções constantes para evitar a ruína de uma obra; a validade, em certos casos, de conservar a obra em estado arruinado; o interesse de se preservar a pátina; a pertinência de completar elementos que se repetem numa mesma obra de arquitetura, por meio de formas simplificadas e materiais diferenciados; a importância da preservação do contexto para a obra de arte ${ }^{4}$. Assim, o autor sintetizou experiências diversas que se sucederam ao longo dos séculos e lançou luzes sobre duas das principais vertentes da restauração no século XIX: uma mais "conservativa" e com grande apreço pelos valores formais da pátina e pelas marcas da passagem do tempo, que teria entre seus expoentes John Ruskin; e outra voltada a completamentos e refazimentos em estilo, cujo mais notório representante, na França, foi Eugène Emmanuel Viollet-le-Duc.

Esse processo de maturação somou-se a formulações teóricas e a experiências sistemáticas, de inventário e de intervenção, que se desenrolaram no século XIX, algumas evidenciando repercussões do positivismo, verificando-se várias vertentes. Entre elas, podem ser citadas as várias restaurações voltadas a monumentos arqueológicos, feitas naquele período, tais como as realizadas por Raffaele Stern e Giuseppe Valadier na ltália, citadas e analisadas por Quatremère de Quincy. Trabalhava-se por meio de consolidação, liberação de ruínas, recomposição com formas simplificadas e com materiais diversos dos originais, fazendo com que a intervenção fosse distinguível da obra original ${ }^{5}$. As obras executadas por eles, sobretudo as do Arco de Tito e do Coliseu, tiveram grande repercussão nas formulações teóricas italianas que se seguiram.

Uma das principais vertentes do século XIX foi a encabeçada por Viollet-le-Duc, que almejava atingir um suposto estado completo de um bem em geral tendo por objetivo a unidade de estilo, havendo uma visão fantasiosa da própria história da arte -, não importando se, para tanto, fossem sacrificadas várias fases da passagem da obra no decorrer do tempo e feitas substituições e alterações maciças. A obra não era entendida em sua individualidade, na
3."Restauration; c'est la réfection de toutes les parties d'un bâtiment dégradé \& dépéri par malfaçon ou par succession de temps, ensorte qu'il est remis en sa première forme, \& même augmenté considérablement, comme celle que le Roi a fait faire au vieux Château de S. Germain en Laye bâti par François I.

Restaurer; c'est rétablir un bâtiment, ou remettre en son premier état une figure mutilée. La plûpart des statues antiques ont été restaurées, comme l'Hercules de Farnese, le Faune de Borghese à Rome, les Lutteurs de la galerie du Grand Duc de Florence, la Vénus d'Arles qui est dans la Galerie du Roi à Versailles; \& ces restaurations ont été faites par les plus habiles sculpteurs". (D'Aviler, 1710,v.2, p. 836).

4. QUATREMÈRE DE QUINCY, 2003.

5. Um exemplo é a restauração do Arco de Tito, em Roma, executada entre 1817 e 1824 por Raffaele Stern e Giuseppe Valadier. Sobreviviam elementos originais apenas na parte central do arco, que esteve durante certo tempo adossado a muros. Foram realizadas escavações que permitiram encontrar a fundação original, possibilitando a reconstituição das proporções primitivas. O arco teve suas partes desmontadas e depois remontadas cuidadosamente em um novo arcabouço de tijolos. Nos elementos reconstituídos (colunas, capitéis, entablamentos, etc.) foi empregado o travertino em lugar do mármore grego, e foram usadas formas simplificadas, permitindo a sua diferenciação das partes originais. 
6. Sobre esses aspectos das proposições de Rus kin, cf. PETRELLA, 1987.

7. Apud CARBONARA 1997 , p. 107-108. A primeira vez em que apare ce a formulação foi em Bulletin Archéologique du Comité Historique des Arts et Monuments, v. 1, p. 47,1839 , depois re tomada nos Annales Ar chéologiques, n.3,p.123, 1845 , em artigo sobre a catedral de Paris, do qual provém a citação de Carbonara. particularidade de seu percurso através da história, mas era vista como fazendo parte de um sistema fechado, remetendo-se a um estilo específico, idealizado.

Outra vertente, que tinha entre seus expoentes John Ruskin e William Morris, preconizava o respeito absoluto pela matéria original. Propunham manutenções constantes para prolongar ao máximo a vida do bem, antecipando, com isso, a atualíssima preocupação com a manutenção e prevenção programadas. Admitiam, porém, a possibilidade de perda de um dado monumento, algo preferível a que contra eles fossem perpetradas "falsificações" e "destruiç̃oes totais", que era a forma como percebiam as restaurações do período. Sua postura era de total descrença na restauração como modo civilizado de intervir em obras do passado, adotando postura favorável apenas às obras de manutenção e conservação. Ademais, Ruskin foi pioneiro na percepção de que os bens culturais e naturais constituem uma fonte preciosa, pois, sendo bens coletivos e não apropriáveis apenas por um indivíduo, podem ser utilizados em benefício de toda a sociedade 6 .

Havia ainda várias posturas ponderadas, que preconizavam o respeito pelo valor histórico e a preservação das marcas da passagem do tempo na obra, temas explorados preferencialmente por arqueólogos e literatos. Nesse sentido, e bastante precoces e ponderadas, foram as colocações, ainda na primeira metade do século XIX, de Adolphe Didron, que afirmou: "No que tange aos monumentos antigos, é melhor consolidar do que reparar, reparar do que restaurar, restaurar do que refazer, refazer do que embelezar; em nenhum caso se deve acrescentar e, sobretudo, nada suprimir"7. É importante salientar que as várias vertentes se manifestavam, com variantes locais, de forma concomitante em diversos países.

Essas experiências díspares e, até mesmo, antitéticas, acabaram sendo analisadas e reformuladas por Camillo Boito no fim do século XIX. Boito amadureceu seus princípios em ambiente de grande efervescência intelectual, em que foram vários os autores que se ocuparam de temas ligados à preservação, cujas obras tiveram repercussão em suas elaborações, a exemplo de Carlo Cattaneo e Tito Vespasiano Paravicini. Paravicini apontava os perigos da falsificação gerada pelas restaurações e preconizava maior respeito pela matéria original, pelas marcas da passagem do tempo e pelas várias fases de uma obra arquitetônica, além de recomendar a distinguibilidade da intervenção. Boito retoma e sintetiza várias proposições que vinham amadurecendo no decorrer do século e consolida uma via para a restauração baseada em sólidos princípios, como: ênfase no valor documental das obras, que deveriam ser preferencialmente consolidadas a reparadas e reparadas a restauradas (retomando, pois, a máxima de Didron); evitar acréscimos e renovações, que, se fossem necessários, deveriam ter caráter diverso do original, mas de modo a não destoar do conjunto; completamentos de partes deterioradas ou faltantes deveriam, mesmo seguindo forma primitiva, ser de material diverso ou ter incisa a data de sua restauração ou, ainda, no caso das restaurações arqueológicas, ter formas simplificadas; obras de consolidação deveriam limitar-se ao estritamente necessário, evitandose a perda dos elementos característicos ou, mesmo, pitorescos; respeitar as várias fases do monumento, sendo a remoção de elementos somente admitida 
se tivessem qualidade artística manifestamente inferior à do edifício; registrar as obras, documentando os trabalhos antes, durante e depois da intervenção; colocar uma lápide com inscrições para apontar a data e as obras de restauro realizadas.

A restauração passa a ser entendida como um "mal necessário", mas trabalhada de modo a domesticar a fúria intervencionista, muito comum entre arquitetos, possibilitando a transmissão de obras do passado, portadoras de inúmeros significados, para o futuro, da melhor maneira possível, ou seja, respeitando seu caráter documental e de modo a efetivamente conservar os valores que motivaram a sua preservação.

Contribuições de inestimável interesse foram feitas por Alois Riegl, na virada do século XIX para o XX, oferecendo meios inovadores tanto para a teoria quanto para a prática da preservação dos monumentos históricos, abarcando aspectos normativos da preservação (no caso, na Áustria) e elaborando análises agudas sobre o papel e as formas de apreender e trabalhar os monumentos históricos. Riegl deu passos fundamentais para consolidar a preservação de bens culturais como um campo disciplinar autônomo, que deixou de ser apenas um "auxiliar" da história da arte lassim como também contribuiu para a consolidação da própria história da arte como um campo autônomo em relação à "história geral"), passando a assumir características próprias, podendo, por sua vez, oferecer contribuições para a própria historiografia e para a criação artística contemporânea. Elaborou proposições prospectivas que contêm elementos que podem ser continuamente explorados e que permanecem válidas ainda hoje ${ }^{8}$.

Naquele período se exacerbava o conflito de dois modos distintos de se entender o trato de monumentos históricos, a conservação e a restauração, algo que já transparece em Didron, na contraposição entre Ruskin e Viollet-leDuc e nas formulações de Boito. Como nota Scarrocchia, as colocações de Riegl deslocaram a polêmica que se verificava entre o conservar e o restaurar, para se buscar, por meio de esforços de conceituação e de atuação prática, uma transformação institucional (e do próprio instituir) da disciplina e oferecer uma nova fundamentação à conservação, diversa daquela da conservação integral e dos restauros inovadores e desrespeitosos em relação ao documento histórico. Procurou estabelecer uma práxis da conservação baseada no respeito pelo valor "de antigo", como um modo de fundamentar a tutela dos monumentos que não mais teria como objetivo, como predominara até então na práxis austríaca, a unidade de estilo. Ou seja, o interesse da tutela não está na retomada de "formas" antigas, mas nos próprios traços de antigüidade?.

As propostas de Riegl tendem ainda a se distanciar da discussão sobre monumentos históricos fundamentada apenas em considerações históricoartísticas, considerando também as formas de recepção, de percepção, de entendimento e teorização do contexto de fruição dos monumentos, por meio dos "valores" por ele explicitados. Ademais, Riegl considerava monumentos históricos não apenas as "obras de arte", mas qualquer obra humana com certa antigüidade (no caso, qualquer obra com mais de 60 anos) e cujo "valor de antigo" era justamente o mais prezado por Riegl. Sobre esse valor ele fundamenta
8. Para uma análise pormenorizada sobre o papel de Riegl para a tutela dos monumentos, em que são também apresentadas e analisadas formulações de variados autores, cf. SCARROCCHIA, 1995.

9. SCARROCCHIA, 1995, p. 91-110. Ver sobretudo o texto de Riegl, Progetto di un'organizzazione legislativa della conservazione in Austria, que faz parte da antologia de textos do autor, organizada e traduzida por Scarrocchia, 1995 p. 171-236; tal texto é composto de três partes: a primeira, justamente o culto moderno dos monumentos, que fundamenta a proposta de lei que se segue, e as discussões na parte final sobre as disposições para a aplicação da lei, em que Riegl elabora também uma série de considerações sobre o valor de antigüidade e sobre a não necessidade da unidade de estilo. 
10. Ver especialmente o texto de Riegl para o projeto de organização legislativa da conservação na Áustria (SCARROCCHIA. 1995, p. 225). as propostas para uma nova legislação e as disposições para sua aplicação, que se seguem ao Culto moderno dos monumentos de 1903, como meio de promover uma tutela difusa para assegurar a preservação dos testemunhos relevantes de épocas passadas, dado o significativo aumento quantitativo dos monumentos históricos.

Riegl preconiza ainda uma distinção clara entre os papéis do conservador e do projetista, entre o momento da conservação propriamente dita, que respeita de modo absoluto aquilo que chegou até os dias atuais, e o momento de projeto, que em alguns casos deve suceder à conservação e se torna uma adição, devendo ser equiparado a um projeto de criação contemporânea. Ou seja, pelo fato de não mais se buscar a unidade de estilo, uma possível adição a uma obra, mesmo que retome formas do passado, não possui valor memorial le só poderá interessar à tutela depois de um período de 60 anos), devendo ser tratada como obra moderna e sujeita ao julgamento, como tal, pela sociedade. Também pelo fato de não postular uma unidade estilística, esse novo elemento poderia ter uma autonomia formal ${ }^{10}$.

Apesar da existência de variadas vertentes, na prática de intervenções foi bastante comum no século XIX e início do século XX a busca de um estado supostamente completo e original, resultando em críticas e ardorosos debates em função das perdas e deformações que geravam nos documentos históricos. A ênfase no valor documental da obra se firmaria no século XX, por meio da atuação de vários profissionais, destacando-se Gustavo Giovannoni, e seria consolidada em âmbito internacional, na Carta de Restauro de Atenas de 1931, que contou com a participação de Giovannoni na sua elaboração e cujas formulações mostram uma repercussão direta das idéias do autor. Giovannoni, como ele próprio explicita, reelabora a teoria de Boito e reforça uma historiografia das teorias de restauro baseada no caminho intermediário, trilhado por Boito e por ele, entre as posições antitéticas de Viollet-le-Duc e de John Ruskin (convém, no entanto, sempre enfatizar que o caminho das teorias de restauração não foi nem linear nem coerente, não havendo relação imediata de causa-efeito). Giovannoni propõe uma classificação sistemática dos casos de restauro: de consolidação, de recomposição (anastilose), de liberação, de completamento e de renovação. Preconiza ainda que os projetos de restauração sejam baseados em estudos rigorosos e classifica metodicamente os casos possíveis, dando maior atenção ao valor documental e histórico do monumento do que ao seu valor artístico e à sua configuração. Filia-se a uma linha positivista de se apreender a arquitetura, não se tendo aberto às contribuições da Estética contemporânea. Os princípios fundamentais por ele enunciados seguem a linhagem de Boito, ou seja, favorecer, antes de mais nada, manutenções, reparos, consolidações, preferencialmente com uso de técnicas modernas; reduzir os reforços ao mínimo necessário para assegurar a estabilidade; respeitar as obras de todas as épocas; caso seja necessário construir adições, datas devem ser inscritas; as adições devem adotar linhas simplificadas, e os completamentos, caso sejam necessários, devem funcionar como "zonas neutras" (tema que gerou e gera, merecidamente, toda uma série de polêmicas). Outro ponto essencial para seu debate teórico e 
na sua atuação prática é a importância dada ao ambiente em que se encontra o bem, que deveria ser tratado com o mesmo cuidado da obra isolada, defendendo a preservação e valorização da chamada arquitetura "menor" "1, dando consistentes passos para a conservação de inteiros conjuntos arquitetônicos e ambientes urbanos.

No entanto, em meados do século XX, fez-se uma releitura dessas proposições, originadas também pelo debate que se sucedeu às destruições da Segunda Guerra Mundial, evidenciando os reduzidos instrumentos teóricos até então empregados para se entender a realidade figurativa dos monumentos. As contribuições da Estética não haviam sido levadas suficientemente em conta, não sendo utilizados meios conceituais para abordar obras e extensas áreas destruídas, o que tornava manifesto também a inadequação de se trabalhar com "neutros" no tratamento de edifícios ou de áreas urbanas.

A partir de meados do século a discussão se aprofundou, alcançandose grande maturidade e equilíbrio. Textos produzidos desde o fim dos anos 1930 foram de grande importância, e muitas das proposições formuladas conservam grande atualidade, a exemplo daquelas contidas nos escritos de Cesare Brandi, Renato Bonelli, Roberto Pane e Paul Philippot. Em âmbito internacional, esse debate conduziria à Carta de Veneza, de 1964, que permanece como referência fundamental do International Council on Monuments and Sites (Icomos, entidade da Unesco). As várias formulações desenrolaram-se paralelamente, convergindo em certos temas e oferecendo meios para a crítica e aprofundamento recíprocos. Autores filiados ao chamado "restauro crítico" assim denominado por se entender a restauração essencialmente como processo histórico-crítico que parte de uma pormenorizada análise da obra e não de categorias genéricas pré-determinadas ${ }^{12}$-, a exemplo de Bonelli e Pane, baseiam suas proposições a partir de uma releitura das transformações históricas por que passaram a teoria e a prática da restauração, articulando-as a outras formulações da época, tais como as de Brandi, que, por sua vez, fundamenta suas propostas essencialmente na Estética e na História.

A configuração do monumento e seus valores formais passam a ser considerados com maior profundidade do que no período precedente, em que predominava o valor documental da obra. Convém ainda lembrar que essa ênfase em relação aos aspectos formais se dava sem desrespeito a seus aspectos históricos e às várias estratificações do monumento no decorrer da história. Desse modo, a restauração deveria ser entendida, na definição de Brandi, como "o momento metodológico do reconhecimento da obra de arte, na sua consistência física e na sua dúplice polaridade estética e histórica, com vistas à sua transmissão ao futuro"13.

A restauração é, portanto, ação de cunho essencialmente cultural e histórico-crítico. Fundamenta-se no reconhecimento que se faz da obra em seus aspectos materiais, como obra de arte e documento histórico. Relevante ainda é retomar o pensamento do mesmo autor ao enfatizar a característica históricocrítica do restauro em contraposição ao empirismo que vigiava até então:
11. Para algumas das colocações do autor, cf. GIOVANNONI, 1925, 1931, 1936.

12. No que se refere às definições de restauração e a uma análise do restauro crítico, cf. CARBONARA, 1997, p. 271-390.

13. BRANDI, 2004, p. 30. 
14. BRANDI, 2004,p. 100 101

15. Sobre esse tema, cf TOLEDO, 2001.

16. CARTA DE VENEZA, 1987

"Conservação:

Artigo $4^{\circ}$ - A conservação dos monumentos exige antes de tudo, manuten ção permanente.

Artigo $5^{\circ}$ - A conservação dos monumentos é sempre favorecida por sua destinação a uma função útil à sociedade; tal destinação é portanto desejável, mas não pode nem deve alterar a disposição ou a decoração dos edificios. É somente dentro destes limites que se de ve conceber e se pode au torizar as modificações exigidas pela evolução dos usos e costumes.

Artigo $6^{\circ}-$ A conservação de um monumento implica a preservação de um esquema em sua escala. Enquanto subsistir, o es quema tradicional será conservado, e toda cons trução nova, toda destruição e toda modificação que poderiam alterar as relações de volumes e de cores serão proibidas.'

17. CARTA DE VENEZA, 1987.

"Restauração

Artigo $9^{\circ}$ - A restauração uma operação que deve ter caráter excepcional Tem por objetivo conservar e revelar os valores estéticos e históricos do monumento e fundamenta-se no respeito ao material original e aos documentos autênticos. Termina onde começa a hipó tese; no plano das reconstituições conjeturais, todo trabalho complementar reconhecido como indispensável por razões estéticas ou técnicas destacarse-á da composição arqui-
Por isso, definindo a restauração como o momento metodológico do reconhecimento da obra de arte como tal, a reconhecemos naquele momento do processo crítico em que, tãosó, poderá fundamentar a sua legitimidade; fora disso, qualquer intervenção sobre a obra de arte é arbitrária e injustificável. Além do mais, retiramos para sempre a restauração do empirismo dos procedimentos e a integramos na história, como consciência crítica e científica do momento em que a intervenção de restauro se produz. [...]

Com isso não degradamos a prática, antes, a elevamos ao mesmo nível da teoria, dado que é claro que a teoria não teria sentido se não devesse, necessariamente, ser verificada na atuação [...].

Por conseguinte, como a restauração não consiste apenas das intervenções práticas operadas sobre a própria matéria da obra de arte, desse modo não será tampouco limitada àquelas intervenções e, qualquer providência voltada a assegurar no futuro a conservação da obra de arte como imagem e como matéria, a que está vinculada a imagem, é igualmente uma providência que entra no conceito de restauração. Por isso é só a título prático que se distingue uma restauração preventiva de uma restauração efetiva executada sobre uma pintura, porque tanto uma como outra valem pelo único e indivisível imperativo que a consciência impõe a si no ato do reconhecimento da obra de arte na sua dúplice polaridade estética e histórica e que leva à sua salvaguarda como imagem e como matéria ${ }^{14}$.

Nota-se que Brandi associa todas as ações voltadas ao monumento à sua definição de restauração ("momento metodológico do reconhecimento"), inclusive a conservação preventiva e os atos de manutenção. Tudo faz parte do processo histórico-crítico vinculado ao restauro. Não existe a separação em categorias distintas e relativamente estanques, a exemplo das formulações que constam da Carta de Veneza, de diferentes graus de ingerência sobre o monumento, tendo-se, em ordem crescente ${ }^{15}$, os processos de manutenção ou reparos, em que se opera, em geral por analogia, com formas e materiais iguais ou semelhantes aos originais lou seja, as ações cotidianas e periódicas que visam a sanar problemas que aparecem na edificação assim que surgem, tais como reparo de um condutor vertical, de uma fiação inadequada, substituição de telhas, de vidros quebrados, etc. - casos em que os problemas não se consolidam como uma cisão, no tempo, na obra como imagem figurada); conservação ${ }^{16}$ e restauração ${ }^{17}$, em que se deveria operar por meio da distinguibilidade.

A restauração, baseada no reconhecimento ${ }^{18}$ da teoria brandiana, deve se pautar na análise da obra em seus aspectos físicos e de sua conformação como imagem figurada, de sua transformação ao longo do tempo, utilizando os instrumentos oferecidos pela filosofia e historiografia da arte, crítica e estética.

Por se fundamentar na relação dialética entre as "instâncias" estéticas e históricas da obra (ou conjunto de obras), essas proposições exigem esforço interpretativo caso a caso, e a intervenção não pode ser enquadrada, a priori, em uma determinada categoria fixa. Cada caso deve ser analisado de modo singular, pelas peculiares características da obra e por seu particular transcorrer no tempo; a intervenção não pode, pois, seguir colocações dogmáticas. No entanto, esse fato não significa que a intervenção seja arbitrária. Apesar de os monumentos serem sempre "indivíduos" e de a teoria tender à generalização, a relevância da teoria reside justamente no fato de se refletir sobre o método para 
se alcançar o conhecimento. Dada a responsabilidade pública envolvida com os monumentos históricos - pelos seus valores simbólicos, históricos e artísticos, perante o presente e o futuro -, deve-se resolver o problema de modo que a idéia subjetiva se torne acessível a um juízo mais objetivo e controlável, que só pode ser alcançado pela reflexão teórica ${ }^{19}$.

Por isso a restauração deve seguir princípios gerais por meio da unidade de metodologia e conceitos consistentes para as várias formas de manifestação artística, mesmo na diversidade dos meios a serem empregados para se enfrentar os problemas particulares de cada obra. É ainda um ato histórico-crítico ancorado na história e na filosofia. Essa vinculação é essencial para aqueles que atuam na preservação de bens culturais, pois possibilita que se supere atitudes ditadas por predileções individuais, que qualquer ser pensante possui, e que se aja de acordo com uma sólida deontologia profissional, alicerçada em uma visão histórica. É importante salientar que esse processo não é óbvio; ao contrário, é um procedimento necessariamente multidisciplinar, que exige estudos e reflexões aprofundadas, não admitindo aplicações mecânicas de fórmulas, exigindo esforços de interpretação caso a caso e não aceitando simplificações.

A restauração deve ainda ter em vista três princípios fundamentais, pensados de forma concomitante:

- Reversibilidade: pois a restauração não deve impedir, antes, tem de facilitar qualquer intervenção futura; portanto, não pode alterar a obra em sua substância, devendo-se inserir com propriedade e de modo respeitoso em relação ao preexistente.

- Distinguibilidade da ação contemporânea: pois a restauração lque é vinculada às ciências históricas) não propõe o tempo como reversível e não pode induzir o observador ao engano de confundir a intervenção ou eventuais acréscimos com o que existia anteriormente, além de dever documentar a si própria.

- Mínima intervenção: pois a restauração não pode desnaturar o documento histórico nem a obra como imagem figurada.

Ademais, a restauração fundamenta-se no respeito pela obra de arte le, na nossa visão contemporânea mais alargada sobre o tema, no respeito pelos bens culturais em geral que, mesmo não sendo "obras de arte", são sempre obras que possuem uma configuração, uma imagem figurada), pela sua materialidade, pelos seus aspectos documentais e tem por objetivo, como exposto na Carta de Veneza, "conservar e revelar os valores estéticos e históricos do monumento"20, ou, como colocado na Carta Italiana de Restauro, de 1972, tem por intuito "manter em eficiência, a facilitar a leitura e a transmitir integralmente ao futuro" ${ }^{21}$ os bens culturais, sem apagar as marcas da translação da obra ao longo do tempo.

Atualmente, constata-se a existência de várias vertentes para se atingir esses objetivos ${ }^{22}$. Pode-se citar aquela denominada "crítico-conservativa e criativa" tetônica e deverá ostentar a marca do nosso tempo. A restauração será sempre precedida e acompanhada de um estudo arqueológico e histórico do monumento."

18. O "reconhecimento" da teoria de Brandi é um processo profundo $\mathrm{e}$ complexo de deixar-se penetrar na obra de arte e no processo que a produziu, reconhecimento do objeto e de sua forma em sua plenitude, buscando, por assim dizer, a sua realidade ontológica. Suas formulações retomam certas proposições, por meio de uma ascendência kantiana, que exploram formulações com repercussões na estética e historiografia de vários autores, como Benedetto Croce, em cuja teoria o juízo de valor tem papel de destaque, Jean-Paul Sartre, Edmund Husserl, Georg Wilhelm Friedrich Hegel.

19. Sobre esses aspectos cf. FRODL In: SCARROCCHIA, 1995, p. 401-412.

20. CARTA DE VENEZA, 1987.

21. Ministero della Pubblica Istruzione [Itália]. Carta del Restauro 1972. In: BRANDI, 2004.

22. No que diz respeito às propostas teóricas atuais referentes ao restauro e referências bibliográficas complementares, cf. CARBONARA, 1997, p. 393439; DETRY, 2000; JOKILEHTO, 1999, p. 213-315; MARCONI, 1999; MIARELLI MARIANI, 2000; FEILDEN, 2003; TORSELLO, 1988. 
ou "posição central", alicerçada na teoria brandiana e na releitura do restauro crítico e da Carta de Veneza. A restauração assume postura conservativa, que não significa congelamento, e não prescinde, antes, propõe, quando necessário, o uso de recursos criativos (utilizados, porém, com respeito à obra e não em detrimento dela), necessários para tratar várias questões que em geral estão envolvidas na restauração, tais como a remoção de adições e a reintegração de lacunas. É a postura fundamentada no juízo histórico-crítico, na análise caso a caso, que exclui qualquer tipo de interpretação mecânica de relação causaefeito.

Outra vertente é a chamada "pura conservação" ou "conservação integral", que privilegia a instância histórica e encara como ações opostas e inconciliáveis, em seu âmago, a restauração e a conservação, retomando uma discussão que tem suas raízes no século XIX e perpassa pelas formulações de autores tais como Didron, Ruskin, Morris, Boito e Riegl. Não trabalha contemporaneamente com a relação dialética das instâncias estética e histórica, que em certos casos poderia resultar em ações tais como a remoção de adições ou tratamento de lacunas com vistas à reintegração da imagem, algo que a corrente da "pura conservação" repudia. Ou seja, essas questões não são abordadas como problema teórico, e a matéria é preservada tal qual chegou a nossos dias, não se atuando por meio de um juízo de valor. Segundo a "conservação integral", deve-se reconhecer que as várias estratificações da obra possam apresentar descontinuidades, admitindo-se uma configuração final com conflitos e, mesmo, contradições. $\bigcirc$ projeto de transformação em si não faz parte do processo de conservação, propondo-se a separação do momento da conservação propriamente dita, que busca perpetuar integralmente os aspectos materiais da obra, daquele da inovação, que se segue à conservação e se assemelha ao projeto do "novo" lao contrário da corrente crítico-conservativa que trabalha de modo concomitante com o momento conservativo e de inovação). Essa postura parte de correntes historiográficas que questionam a existência de testemunhos relevantes, e outros nem tanto, para a história. Para responder de modo afirmativo, deveria ser possível um conhecimento total, algo que a reflexão histórica nega, enfatizando que juízos historiográficos são sempre relativos e o conhecimento do passado é limitado. Um juízo histórico-crítico "infalível" não existe, sendo uma invenção positivista do Oitocentos e, portanto, não se deveria julgar, devendo-se privilegiar a instância histórica, ou seja, preservar o documento em sua integridade. Na vertente crítico-conservativa, o juízo histórico-crítico tem de ser baseado na história da arte e na estética, justamente para que seja um juízo, e não um ato arbitrário, tendo-se plena consciência de que possui pertinência relativa. $\bigcirc$ momento da criação, na "pura conservação", comporta-se como adição à obra, excluindo, assim como na vertente "crítico-conservativa", qualquer possibilidade de imitação ou mimetismo, conferindo ainda imenso espaço para a liberdade expressiva.

No pólo oposto, encontra-se a chamada "manutenção-repristinação" ou "hipermanutenção" que propõe o tratamento da obra por meio de manutenções ou integrações, ordinárias e extraordinárias, retomando formas e técnicas do 
passado. Como nota Torsello, esta última postura origina-se num pragmatismo de base, parte da própria obra e baseia-se numa lógica indutiva, enquanto a teoria brandiana tem por base, ao contrário, uma lógica dedutiva fundamentada em axiomas éticos e científicos ${ }^{23}$, e depois, sim, volta-se para a análise pormenorizada da obra em seus aspectos materiais, formais e históricos. Tanto a "posição central" quanto a "pura conservação" preconizam e valorizam a diversidade, enquanto na "manutenção-repristinação" permanece certo pragmatismo, com tendência a se trabalhar por analogia (mas sempre de modo limitado).

Essas várias vertentes têm representantes em diversos países. É importante salientar que todas elas, apesar de operarem de maneira distinta, preconizam um respeito absoluto pelo valor documental e pelos aspectos históricos da obra, mesmo na pluralidade de suas formulações. Seus preceitos teóricos permitem circunscrever, de maneira pertinente, o campo da preservação como campo essencialmente cultural.

A restauração, como formulada por Brandi, no restauro crítico, na Carta de Veneza, e como retomada pelo restauro crítico-conservativo, é ato crítico que, alicerçado no reconhecimento da obra de arte e de seu transformar no decorrer do tempo, insere-se no tempo presente. Jamais deveria colocar-se em qualquer uma das fases por que passou a obra ${ }^{24}$ (muito menos no momento de sua criaçãol e não deveria propor a imitação. Deve sempre ser ato de reinterpretação histórico-crítico voltado para a transmissão do bem para as próximas gerações e, portanto, uma ação que mantém sempre o futuro no horizonte de suas reflexões.

Por ser ato histórico-crítico, a restauração possui pertinência relativa, em relação aos parâmetros culturais (e socioeconômicos, políticos, etc.) de cada época e também no que se refere àqueles de épocas anteriores e posteriores. Não é possível prever quais serão os critérios empregados no futuro que, com toda certeza, serão diversos dos atuais. Isso repercute inclusive na tarefa basilar da preservação, o inventário, que também é resultante da visão de um dado presente histórico e possui pertinência relativa. A preservação de monumentos históricos deve, por isso, ser discutida e enfrentada com os instrumentos e vinculada à realidade de cada época, e o fato de, no futuro, as posturas serem diversas não exime um dado grupo social da responsabilidade pela preservação dos bens culturais ${ }^{25}$ e evidencia ainda mais a necessidade de se agir, sempre, de modo crítico e fundamentado (na história e na estética, para evitar arbitrariedades) em relação ao legado de outras épocas, pois somos responsáveis pelos nossos atos perante o presente e as gerações futuras.

As formulações teóricas vinculadas à restauração permitem que pelo menos se circunscreva e se defina o campo de ação de maneira adequada e fundamentada, separando-o daquilo que exorbita completamente dos objetivos da preservação; pois uma coisa é possuir uma pertinência relativa; outra é ser de todo impertinente ao campo. Na prática têm-se verificado, porém, numerosas ações em bens culturais que não respeitam o documento histórico, sua configuração, seus aspectos memoriais e tampouco as especificidades e características dos materiais de que são compostos: ocorrem, mas não poderiam
23. TORSELLO, 1988, p. 24.

24. Sobre os "tempos" da obra de arte, cf. BRANDI, 2004, p. 21-27; BALDINI, 1997 , v. 1.p. 5-15.

25. Isso é exposto logo na abertura da Carta de Veneza

"Portadoras de mensagem espiritual do passado, as obras monumentais de cada povo perduram no presente como o testemunho vivo de suas tradições seculares.A humanidade, cada vez mais consciente da unidade dos valores humanos, as considera um patrimônio comum e, perante as gerações futuras, se reconhece solidariamente responsável por preservá-las, impondo a si mesma o dever de transmitilas na plenitude de sua autenticidade."

Também Brandi (2004, p. 31) afirmara que o fato de se reconhecer a obra de arte como tal impõe a quem reconhece o imperativo moral da sua conservação: "Na verdade, apesar de o reconhecimento dar-se sempre na consciência singular, naquele mesmo momento pertence à consciência universal, e o indivíduo que frui daquela revelação imediata impõe a si próprio o imperativo categórico como o imperativo moral, da conservação." 
26. LA REGINA, 1992 p. 15 .

ser classificadas como ações de preservação lapesar de se autodenominarem como tal), pois são ditadas essencialmente por razões econômicas, políticas ou utilitárias e não respondem a preceitos teóricos de qualquer ordem. São ações pragmáticas, e não culturais, podendo conduzir a resultados que vão contra os próprios objetivos da preservação, a saber: tutelar e transmitir para o futuro, da melhor maneira possível, um bem cultural, respeitando seus aspectos materiais, históricos, formais e simbólicos.

Qualquer proposta de restauração para uma obra arquitetônica, incluindo-se o tratamento de superfícies, deveria, pois, ser ato fundamentado, conseqüência de esforços multidisciplinares que envolvam acurada pesquisa histórico-documental, iconográfica e bibliográfica, pormenorizado levantamento métrico-arquitetônico e fotográfico do(s) edifício(s), exame de suas técnicas construtivas e dos materiais, de sua estrutura, de suas patologias, e análise tipológica e formal. Fatores esses que levam ao entendimento das várias fases por que passou a obra (ou conjunto de obras) no decorrer do tempo e de sua configuração e problemas atuais. Mas a intervenção se resolve também por meio do desenho, do projeto de restauração que deve prefigurar a ação. Tratase de projeto de arquitetura, nada simples, que se deve articular ao processo de aquisição de dados e análises, que não é acessório, e sim fundamental. Esse processo tem de levar o tempo condizente para se efetuar, e para que amadureçam, levantamento, análises e propostas, não se devendo admitir soluções apressadas em nenhuma das fases - estudos, projeto e execução -, que podem levar a danos irreparáveis.

O conhecimento aprofundado deveria conduzir à compreensão e, por conseguinte, ao respeito pela(s) obra(s), requisito essencial quando se trata de bens culturais. Pois intervir num bem de interesse cultural, que possui papel memorial e interesse formal, histórico e simbólico, é ato de extrema responsabilidade, pois se trata, sempre, de documentos únicos e não reproduzíveis. Essa percepção deveria levar à conscientização, pelo fato de qualquer intervenção de modo forçoso alterar o bem, de que uma mudança não controlada leva a perdas irreparáveis, devendo-se sempre enfatizar que os organismos históricos são muito delicados. É fato incontestável que qualquer intervenção implica mudanças que por sua vez, como explicita La Regina, implicam destruição (que deve se restringir ao mínimo possível), mas não devem "alterar ilicitamente" a consistência física e formal dos bens ${ }^{26}$, daí a relevância de qualquer ação ser conseqüência de processo histórico-crítico judicioso e fundamentado. Por isso é importante trabalhar, sempre, com equipes multidisciplinares capacitadas, e os profissionais ligados à preservação devem possuir visão "histórica" e sólida formação e consciência da responsabilidade envolvida, baseando-se em uma deontologia profissional apropriada para não recair no arbítrio.

Os instrumentos oferecidos para a preservação por meio das vertentes teóricas ligadas ao campo são adequados para ałuar em monumentos históricos, sem deformar e deturpar o documento, a memória, os bens legados pelo passado, 
que são parte integrante de nosso presente. Monumentos históricos, é importante repetir, são únicos e não reproduzíveis e devem portar consigo para o futuro seus elementos caracterizadores e as marcas de sua translação no tempo; todo cuidado é pouco, pois esses monumentos-documentos, instrumentos e suportes materiais da memória, individual e coletiva, permitem infinitas possibilidades de atualização ao longo do tempo, por um grupo social ou por uma consciência individual, oferecendo, sempre, renovadas leituras; serão cada vez percebidos e apreendidos de modo diverso e podem, continuamente, de diferentes modos, por esta e pelas gerações do porvir, oferecer instrumentos importantes para a reflexão e, por conseguinte, para a adaptação a uma sempre mutável realidade.

$\bigcirc$ tratamento das superfícies dos monumentos deve, pois, fazer parte desse processo histórico-crítico. No entanto, em muitas intervenções recentes, o tratamento das superfícies não tem sido encarado dentro desse processo, predominando repintes aleatórios, substituições e refazimentos superficiais ex officio, sem nenhum tipo de reflexão sobre o estado em que se encontram as superfícies nem sobre seu papel como testemunho privilegiado do transcurso de um dado bem, ou seja, como documento histórico e como palco de transformações figurativas. Na maioria das vezes, nem mesmo se cogita a utilização de técnicas para se consolidar e tratar o existente, que visassem a preservar as marcas da translação da obra no tempo ${ }^{27}$.

Esse "rejuvenescimento" forçado de nossos bens culturais faz parte, na verdade, de um fenômeno mais amplo, que se acentuou em tempos recentes: a busca de juventude a qualquer preço, que também acaba por repercutir no trato dos monumentos históricos, que passam a ter a obrigação de parecer novos. Riegl já chamava a atenção para esse problema. Ao analisar as várias maneiras que uma dada sociedade percebe e se apropria de seus monumentos históricos, comenta os "valores de contemporaneidade", ou seja, aqueles valores derivados do fato de os bens culturais corresponderem a uma expectativa dos sentidos (valor de uso) ou do espírito (valor artístico), podendo satisfazê-las tão bem quanto as criações modernas. Quando avalia o "valor artístico", uma das categorias que evidencia é o "valor como novidade" (a outra é o "valor artístico relativo"), em que se equipara um monumento histórico a uma criação recente, exigindo dele uma integridade perfeita de formas e cores. $\bigcirc$ autor afirma que esse tipo de ação pode ser apreciada de forma mais fácil até por pessoas desprovidas de cultura, e o "valor como novidade" sempre foi o mais prezado pelos menos cultivados. Ao abordar esse aspecto, pondera também sobre a repercussão desse fenômeno no trato dos monumentos, afirmando que aos olhos das massas, apenas aquilo que é novo e intacto é belo, sendo o velho, feio. Foi necessário percorrer um longo caminho desde as restaurações estilísticas que predominaram no século XIX, em que a busca anti-histórica do estado original era uma constante, até uma situação culturalmente mais diversificada e rica se consolidar, com uma crescente apreciação daquilo que Riegl denomina "valor de antigo" - cujo respeito é a pedra fundamental das suas propostas para a reorganização legislativa da proteção dos monumentos na Áustria -, do qual a eficácia estética
27. Sobre o tratamento das superfícies e a cor em edifícios históricos existe uma abundante literatura. Antes de mais nada, em âmbito brasileiro, cf. OLIVEIRA, 1995. Para questões de análises de princí pios e o conseqüente tratamento cf. MORA; MORA, 1984; PHILIPPOT; MORA; MORA. 1984; FIORANI, 2000. Para uma visão pragmática,com recomendações para a recuperação de superfícies de interesse histórico, cf. ASHURST;ASHURST.1989. Para a discussão de princípios gerais, cf. BRANDI, 1994, p. 54-60; CARBONARA, 1997,p. 511-560;MARCONI, 1988; MIARELLI MARIANI, 1995. 
28. RIEGL, 1984, p. 89109.

29. Roberto Pane já chamava a atenção para o assunto em texto de 1968 , Restauro d'arte e responsabilità culturale:" $[\ldots] \mathrm{Vi}$ è poi un altro genere di scempi, da ascrivere invece alla pura e semplice ignoranza attiva, e che trae origine dall'assoluta in comprensione per l'interesse verso ciò che è antico e che, in quanto tale, porta in varia misura segni della consunzione e della fatiscenza.

L'ignoranza e l'insensibilità che ad essa normalmente si accompagna, irride a quegli aspetti accidentali e gratuiti che definiscono la stratificazione storica, e preferisce ad es si l'evidente efficienza e 'pulizia' dei materiali nuovi." (PANE, 1987, p. 310)" e o interesse residem, justamente, nos sinais da passagem do tempo e, inclusive, da degradação ${ }^{28}$.

Sinais de transcurso do tempo são cada vez menos apreciados em nossa sociedade ${ }^{29}$. Com essa tendência atual à renovação e à pasteurização de superfícies, muito se perde da riqueza e da vibração resultantes dos próprios métodos de execução tradicionais de argamassas e de pinturas e dos "acidentes" da vida de uma obra. Deve-se lembrar que o objetivo de uma restauração não é oferecer uma imagem do passado facilmente consumível, simplificada de forma grosseira para se tornar mais palatável ao gosto massificado. É, ao contrário, explorar e valorizar toda a riqueza das diversas estratificações da história. Isso pode ser alcançado por meio do ato histórico-crítico, antídoto para a tendência atual de se voltar para cores frívolas - que em nosso ambiente muitas vezes se está traduzindo em cores berrantes que chegam a impedir a própria apreciação do bem, tal a cacofonia que impõem à obra - ou para cores amorfas, que não se relacionam com as características tectônicas e de composição da obra. $\bigcirc$ interesse em preservar as marcas do transcorrer do tempo não é mero "ruinismo" ou necrolatria, mas é, sim, uma apreciação estética, crítica, histórica, que não considera o tempo como reversível. Deve-se, porém, de modo semelhante ao que se passa com a análise da edificação como um todo, reconhecer aquilo que pode ser considerado como incidência positiva do tempo sobre a obra, a exemplo da pátina, e aquilo que, ao contrário, deve ser visto como incidência negativa, tais como sujeiras e patologias. São coisas distintas, que devem ser encaradas e tratadas de modo diverso.

As situações possíveis, no que se diz respeito ao estado das superfícies, podem variar enormemente. Mas, no que concerne à teoria da restauração, pode-se especificar que uma vez que se reconhecem como válidas e merecedoras de preservação as várias fases por que passou a obra no decorrer do tempo como já preconizavam as recomendações do Congresso de Engenheiros e Arquitetos Italianos de 1883, a Carta de Atenas de 1931 e a Carta de Veneza, de 1964, entre outras - esse raciocínio também deveria ser aplicado ao tratamento das superfícies.

Um fenômeno que se tem acentuado nos últimos anos no trato dos bens culturais, de um modo geral, é a cisão entre teoria e prática, algo que também se aplica ao tratamento de superfícies: de um lado existem as vertentes teóricas da preservação que preconizam o respeito pelas características materiais e pelas várias estratificações de uma dada obra; do outro, quando se trata de superfícies, as renovações totais tornaram-se preponderantes, como se fosse o único caminho plausível, quase uma solução automática. Na linha da hipermanutenção-repristinação o tratamento de superfícies é considerado como processo de manutenção; ou seja, as superfícies (argamassas e pinturas) são consideradas camadas de "sacrifício" que, para a proteção do bem, devem ser renovadas periodicamente. Mas cabe lembrar que essa não é a única vertente teórica e que as outras linhas obtiveram sólidos e numerosos êxitos, baseados em experimentações conscienciosas na prática. Deve-se ainda enfatizar que 
todas as vertentes se fundamentam em formulações teóricas; algo bastante diverso de simplesmente repintar e renovar, sem nem mesmo refletir sobre o assunto.

É importante recordar que se por um lado a superfície é a "pele" do edifício, e não simples roupagem, e, por isso, o "órgão de choque" por excelência em relação ao ambiente hostil (sol, chuva, mudanças de temperatura, polvição, etc.), sujeita, portanto, a várias formas de degradação que devem ser enfrentadas, por outro, é também testemunho privilegiado do decorrer da história, adquirindo valores figurativos, muitas vezes positivos, que não podem ser pura e simplesmente desprezados na busca da fonte da eterna juventude.

Os valores, plásticos e simbólicos, das marcas da passagem do tempo sobre os objetos têm sido apreciados por autores variados e de diferentes épocas, que evidenciam que as modificações impostas pelo tempo nem sempre são danosas, muitas vezes se comportando, ao contrário, como um valor que se agrega à obra, conferindo-the uma diferenciada beleza que reconhecemos na superfície dos monumentos naquilo que chamamos pátina. Um exemplo pode ser dado por Quatremère de Quincy:

A idéia de antigüidade imprime nos monumentos, assim como nos homens, um caráter de respeito e de veneração. Admiramos neles essa predileção da sorte que os salvou da mão do tempo; eles nos parecem privilegiados; apenas o fato de sua conservação os torna para nós objetos maravilhosos. A imaginação congrega facilmente sobre eles um número infinito de relações que nos transportam quase que realmente para a época recuada que os viu nascer. Não é absolutamente apenas uma ilusão do espírito; existe uma verdade nessa aproximação. Meus olhos vêem aquilo que foi visto por Péricles, por Platão, por César. Horácio e Virgílio passaram defronte a essas colunas que admiro. Admiramos, portanto, os mesmos objetos, tocamos as mesmas belezas. [...]

A graça da vetustez deve-se, pois, à certeza, mas, também, à aparência da vetustez. Eis por que é tão precioso aos olhos do amador esse verniz do tempo, que se busca freqüentemente desfazer. Dar de novo a esses restos mutilados uma integridade mentirosa, apagar e fazer desaparecer das obras antigas a marca da antigüidade e dar-thes um falso ar de juventude, é delas tirar, em parte, seu valor e sua beleza, e essa espécie de inviolabilidade que as protegia dos ataques do espírito de crítica.

Pois a antigüidade tem de, algum modo, a vantagem de subtrair os monumentos à censura $[\ldots]^{30}$.

evocado:

Pode-se ainda retomar um texto de Marguerite Yourcenar, freqüentemente

[...] Esses duros objetos, talhados à feição de formas da vida orgânica, sofreram, à sua maneira, o equivalente da fadiga, do envelhecimento, do infortúnio. Eles se modificaram como o tempo nos modifica. [...]

Algumas dessas modificações são sublimes. À beleza tal como a quis um cérebro humano, uma época, uma forma particular de sociedade, é acrescentada uma beleza involuntária, associada aos acasos da história, devidas aos efeitos de causas naturais e do tempo ${ }^{31}$.

Existe, como dito, uma variedade enorme de situações ao se afrontar o tratamento de superfícies. $\bigcirc$ quesito basilar é o juízo histórico-crítico, procurandose diferenciar os aspectos positivos, a pátina, e os negativos, as patologias,
30. QUATREMÈRE DE QUINCY, 1989, p. 66-67.

31. YOURCENAR, 1983, p. 61-62. 
resultantes da ação do tempo. Estes últimos devem ser tratados. Devem ser

33. No que se refere ao equilíbrio cromático, cf. BALDINI, 1997.

34. As análises de Philippot referem-se à patina em relação às pinturas. $\mathrm{O}$ autor afirma: "D'autre part, dans la mesure même où ces modifications sont irréversibles et échappent à une détermination rigoureuse, il faut admettre que l'état original de l'œuvre, c'està-dire celui dans lequel l'artiste l'a laissée lorsque s'est achevée le processus de création, est en tout état de cause impossible à rétablir, et même à déterminer objectivement. Aucune restaura tion ne pourra donc jamais prétendre rétablir l'état original d'une peinture. Elle ne pourra que révéler l'état actuel des matières originales. A supposer qu'elle le veuille, elle ne peut donc en aucun cas abolir l'historicité seconde de l'œuvre, le temps qu'elle a traversé pour se présenter à nous." (PHILIPPOT, 1966 p. 139).

35. Para recomendações cf. MORA; MORA, 1984 p. 23-24 suprimidas as causas de degradação, a exemplo da umidade ascendente e descendente e da sujeira. No entanto, é preciso ter cuidado ao realizar a limpeza, pois ela deve respeitar a incidência positiva do tempo sobre a obra, ou seja, preservar a pátina - não sendo esse um mero problema técnico como enfatiza Paul Philippot, mas também crítico -, e jamais buscar estratos intocados. Como bem expôs Brandi, em trecho dedicado à pintura e à escultura, mas plenamente aplicável a obras arquitetônicas:

Mas nem sequer se poderia considerar a pátina como um conceito da era barroca. Já Vasari, no Trattato della Scultura transmite até mesmo as receitas das pátinas artificiais que em seu tempo se aplicavam ao bronze. Também isso convida à reflexão. Se a sensibilidade dos artistas do Renascimento se afastava, para o bronze, do brilho do novo, daquela prepotente jactância da matéria nova, seria possível que não se buscasse igualmente atenuar a virulência descarada da cor, o fausto demasiado evidente das terras, lacas, ultramarinos? A prevalência da matéria sobre a forma se dá toda em prejuízo da forma: a matéria, na obra de arte, deve ser trâmite para a imagem, não é jamais a própria imagem. [...] $\bigcirc$ ofício da pátina nos revela então isso: atenuar a presença da matéria na obra de arte; reconduzi-la ao seu ofício de trâmite, detê-la no limiar da imagem de modo a que não o ultrapasse com uma inadmissível prevaricação sobre a forma ${ }^{32}$.

A limpeza deve ser feita ainda de modo a respeitar os vários materiais que compõem a fachada e seus valores cromáticos, pois pode desequilibrar a relação entre eles, dado que os diferentes materiais numa mesma obra se alteram de modo distinto e alguns sofrem transformações irreversíveis. Se o objetivo da restauração é facilitar e valorizar a leitura de um dado monumento, é um dever fazer a análise conscienciosa dos materiais e do equilíbrio cromático da composição da fachada, para que seja respeitado e não se criem dissonâncias indesejáveis ${ }^{33}$.

Deve-se, pois, de um modo geral, preservar o que existe, sem procurar regularizar e "embelezar". Philippot afirma o que se deve buscar numa restauração é revelar o estado atual das matérias originais e jamais pretender restabelecer seu estado original numa tentativa de abolir o tempo atravessado pela obra ${ }^{34}$.

É necessário respeitar as argamassas e cores existentes, em suas várias estratificações, mantendo-as e consolidando-as, tratando lacunas, protegendo as superfícies sem que isso implique automaticamente um refazimento total ou parcial da argamassa e de sua cor $^{35}$. A cor, ou as várias composições de cores que recebeu um dado edifício no decorrer de sua história, é também um problema a ser analisado de forma crítica, caso a caso, procurando distinguir aquilo que é estratificação histórica válida e coerente daquilo que é simples "crônica". Devem-se verificar a composição e o estado das argamassas; os estudos estratigráficos revelam-se da maior importância para entender as várias fases colorísticas porque passou o edifício, sendo instrumentos valiosos para entendêlo e para analisar as transformações do "gosto histórico" e o modo como o bem foi percebido e tratado no decorrer do tempo.

As situações possíveis também tomam as mais variadas formas. Em alguns exemplos, mais raros, em que o estrato original seja de grande valor e 
na maior parte existente e em que as estratificações posteriores possuam pouco interesse, pode-se propor um retorno à camada original, por meio de cuidadosos trabalhos de remoção das camadas mais recentes, seguidos de limitadas integrações, consolidação e proteção.

Ou, casos mais freqüentes, a restauração deve respeitar as transformações do edifício no decorrer do tempo, por meio de intervenção que permita e facilite a leitura de sua complexa história, conservando visíveis as várias fases cromáticas do edifício, sem que isso comprometa sua apreciação como obra que possui uma configuração. Ou, ainda, por exemplo, no caso de edifícios que receberam diversas camadas de argamassas no decorrer do tempo, que se encontram desagregadas, deterioradas e não possuem maior interesse histórico, além de muitas vezes comprometerem as camadas originais /a exemplo de recobrimentos recentes de cimento sobre argamassas originais à base de call, pode-se propor a remoção dessas adições posteriores, a consolidação do existente e o tratamento das lacunas. Mas, qualquer que seja a situação, a resposta só deveria ser dada em função de uma análise acurada e fundamentada.

Existem também situações em que, por uma série de razões, a serem ponderadas com cautela, extrema cautela, possa ser necessário renovar a $\operatorname{cor}^{36}$. Dado que nas formulações teóricas da restauração se recomenda respeitar as diversas fases da história de um edifício, suas várias estratificações, e também se afirma que a busca do estado original não é um objetivo a ser perseguido pois significaria uma vontade deliberada de apagar o transcorrer do tempo, considerando-o como reversível, o que jamais é o objetivo da restauração ${ }^{37}$ cabe especular sobre o que se deve fazer, segundo esses preceitos teóricos.

As situações também podem ser as mais variadas. Se a composição de cor que o edifício apresenta na atualidade não estiver consolidada na imagem do próprio monumento (caso em que deverá ser preservada), deve-se, por meio do ato crítico, propor novas cores baseadas numa reinterpretação da obra hoje, que, raríssimas vezes, a serem ponderadas com muita cautela, podem ser coincidentes com a composição primitiva. Na verdade, isso seria uma quase impossibilidade teórica, pois a restauração, como explicitado, é sempre ato crítico do presente e não propõe o tempo como reversível.

Em muitas intervenções recentes, porém, volta-se de modo imponderado ao uso das cores originais, convertendo essa volta num álibi cômodo, como se as cores (supostamente) originais tivessem por si só uma autoridade irrefutável e subtraíssem a intervenção da responsabilidade por uma proposta fundamentada e de qualquer julgamento crítico, resultando em renovações inconsideradas e o mais das vezes mal executadas, ademais com materiais inapropriados.

Mas cabe chamar a atenção para um problema fundamental: fazer uma nova proposta de cores para um edifício implica saber ler a obra como imagem figurada, analisar profundamente as suas características tectônicas, e para isso é necessário um sólido conhecimento da história da arquitetura. A cor na arquitetura é tema da maior relevância, importante para se entender e valorizar a articulação dos elementos, das fachadas e dos espaços internos e fundamental na percepção que se tem da volumetria do edifício, sendo determinada segundo
36. Sobre essa discussão, cf. CARBONARA, 1997. Em especial o capítulo Il trattamento delle superfici come problema di restauro, p. 511-519. Ao comentar casos em que, por razões culturais ou não, torna-se necessária a renovação cromática das fachadas, Carbonara assevera (p. 517): "In questi casi l'intervento non dovrebbe però assumere carattere competitivo o prevaricante rispetto alla figurazione nella quale s'innesta, né risultare imitativo o mimetico nei riguardi dell'immagine architettonica poiché seguendo tali modi si recherebbe una grave alterazione ai valori storici ed artistici del monumento. Pertanto il nuovo colore non dovrebbe ripetere quello originario, od uno fra gli altri che lo hanno seguito, dato che esso non si colloca come sostituzione dell'una o dell'altra tinta; il suo inserimento non è rivolto a riempire il vuoto cromatico registrato sull'intonaco, ma a costituire un'aggiunta 'critica', cioè l'unico apporto che l'odierna cultura storico-artistica può legittimamente recare alla soluzione del problema. Si tratta perciò d'un intervento che non è fondato sopra una scelta di gusto o 'filologica', ma che è invece il risultato di un'analisi e di un giudizio critici, proprio perché il restauro è un'ipotesi critica, non una creazione sovrapposta od integrativa dell'opera architettonica."

37.A esse respeito, ver o texto de Cesare Brandi, Intonaci, colori e coloriture nell'edilizia storica. (BRANDI, 1994,p. 54-60). $\mathrm{O}$ autor exalta a importância do tema e o considera não menos impor- 
tante do que a questão da pátina ou dos vernizes no restauro de pinturas. $\mathrm{Co}_{-}$ mentando as transformações no Palácio de Montecitorio em Roma, afir ma (p. 56): "Quindi, non già proporsi l'intento storicamente assurdo, di risalire al tempo dell'inter vento del Fontana per ristabilire un colorito, che in nessun modo può essere recuperato o ricos truito nel presente. Quin di, non solo non si potrebbe tornare indietro, alla prima ideazione del Bernini, ma neppure regredire ad uno stato ottimale raggiunto dal Fontana, scartando quello che è il passaggio del tempo sull'opera d'arte." uma lógica compositiva que não pode ser tratada de modo aleatório. Se o objetivo da restauração é facilitar e valorizar a leitura de um dado monumento, trała-se de fazer uma nova composição que cumpra essa função por meio do ato criativo. Não se trata de uma livre e arbitrária sobreposição de tinta. É um engano grosseiro pensar que se possa fazer uma pintura aleatória, usando como justificativa o fato de que a pintura poderá ser refeita num futuro próximo. Não se trata de uma vestimenta que pode ser mudada quando bem aprouver. Por menos que dure, uma pintura permanece num monumento, no mínimo, por vários meses, e, em geral, por anos, e pode causar danos significativos para sua percepção e apreciação.

Além do mais, as técnicas empregadas e o tipo de tinta devem possuir permeabilidade, textura, tonalidade, luminosidade, consistência e transparência compatíveis com os substratos existentes (que devem ser respeitados), devem ser adequadas aos materiais (lembrando que materiais distintos requerem tipos de tintas diferentes) e à própria composição arquitetônica do edifício. As atuais tintas à base de polímeros (tais como as acrílicas ou PVA), produzidas industrialmente, que em si podem ser de excelente qualidade, e que têm sido empregadas de modo indistinto em intervenções em bens culturais, não preenchem esses quesitos quando se trata de pinturas tradicionais à base de cal sobre argamassas também à base de cal, podendo resultar em uma imagem rejuvenescida de modo artificioso, uniforme - fazendo com que se perca toda a vibração das argamassas e pinturas tradicionais -, com tonalidades inadequadas e aparência um tanto "plastificada". Além disso, esse tipo de tinta não é conveniente para as próprias argamassas históricas à base de cal, documentos importantes do modo de construir de uma época, pois não permitem que a argamassa "respire". Pela diferença de permeabilidade entre os estratos antigos e a nova pintura, ocorrerá a desagregação dos componentes, deterioração e desprendimento da massa antiga, condenando um documento histórico relevante a um processo acelerado de degradação, aquilo que uma restauração, com efeito, deveria evitar. Existem alternativas viáveis, tais como: tintas à base de cal, que são perfeitamente compatíveis com as argamassas antigas de mesma base, mas possuem o inconveniente de ter duração efêmera em atmosferas poluídas sujeitas a chuvas ácidas, como é o caso da cidade de São Paulo, e são de difícil fixação; tintas à base de silicato de potássio, compatíveis com substratos à base de cal ricos em sílica, que são duráveis, permeáveis ao vapor d'água e compatíveis com argamassas históricas, devendo, porém, ser usadas com muito cuidado e preferencialmente aplicadas com pincel; devem ser empregadas apenas sobre argamassas pintadas anteriormente com tintas à base de cal, caso contrário pode ser necessário refazer a argamassa; podem ainda ser feitas veladuras sobre a superfície, aplicando-se um tipo de pintura pelicular à base de resina acrílica diluída (que não deve de modo algum ser confundida com tintas acrílicas industrializadas), misturada com corantes naturais, sendo pouco espessa e não recobrindo totalmente o existente; possui transparência e permeabilidade compatíveis com as argamassas e tintas tradicionais e deve ser 
aplicada sobre uma demão muito fina de reboco como fundo, em camadas muito sutis, como veladura, justamente ${ }^{38}$.

No que se refere às tintas à base de silicato, é muito importante estar atento para as tonalidades a serem empregadas e para o fato de se tratar de uma tinta durável e estável. Mesmo quando se "apela" para a cômoda e imponderada volta às supostas "cores originais", é importante lembrar que as pinturas tradicionais eram menos duradouras, "lavavam-se", e suas tonalidades feitas com corantes naturais, que por si só eram, em geral, mais suaves do que aquelas obtidas com colorantes artificiais, atenuavam-se com maior rapidez. É muito importante ter cuidado na escolha dos tons, relembrando ainda uma vez Brandi, sobre a importância de se atenuar a "jactância" da matéria para que essa não se torne preponderante sobre a forma, pois, mesmo que essas pinturas não causem danos físicos ao edifício, dependendo da escolha de cores e tonalidades, podem resultar em danos figurativos da maior gravidade.

Também para conjuntos arquitetônicos ou centros históricos, o tema das superfícies deve ser encarado, de modo completivo, como ato históricocrítico. Em tempos recentes tem havido uma alternância entre intervenções que buscam ora voltar às cores originais - esquecendo-se, além das questões evocadas acima que, com freqüência, em conjuntos urbanos as edificações podem não ter convivido nunca, na mesma época, com suas cores originais, pelo fato de terem sido construídas em momentos diferentes e, quando da conclusão dos edifícios posteriores, os mais antigos, com muita probabilidade, não mais apresentavam sua coloração de origem -, ora realizar intervenções livres com cores extremamente fortes, preponderantes, que não valorizam os aspectos históricos nem as características formais dos edifícios, não possuindo relação com a conformação arquitetônica, dificultando a leitura e a própria apreciação das obras, levando, ademais, a uma infantilização da imagem. O ideal seria trabalhar por meio de planos de cor, entendendo-se com isso, segundo sugestão de Bonellij ${ }^{39}$, limitar a intervenção ao mínimo e mudar o menos possível a imagem que se consolidou com o tempo.

Importante é ainda lembrar, retomando o problema das cores originais, que tanto para obras isoladas quanto para conjuntos arquitetônicos, a configuração da área envoltória pode ter se alterado de tal modo que a utilização dessas cores seja prejudicial para a apreciação das obras ou conjuntos. Pois uma coisa é um edifício na sua situação primitiva, isolado em um quarteirão ou inserido com largueza em um grande terreno, ou rodeado por edificações de pequena altura, ou ainda um conjunto arquitetônico circundado por edificações de pequeno porte; outra coisa totalmente diversa é uma obra ou conjunto de obras que, na atualidade, encontram-se encerrados entre edificações de alto porte construídas no decorrer do tempo. A percepção da(s) obra(s), nesses casos, altera-se completamente, e a proposta da composição de cores deve ser feita em função dessa nova realidade, sempre enfatizando que não se trata de aleatória sobreposição de tinta, nem de um elemento secundário, que pode ser mudado de acordo com as circunstâncias e vontades, mas, sim, de reinterpretação responsável e fundamentada.
38. Para um breve relato sobre os tipos de pinturas, origem dos dados apresentados e referências bibliográficas complementares, cf. CARBONARA, 1997, p. 551-560; OLIVEIRA, 1995.

39. CARBONARA, 1998 
Também no que se refere às intervenções em superfícies feitas com a chamada "massa raspada", ou seja, uma argamassa concebida para ser aparente, sem pintura, e fazendo as vezes de um revestimento de pedra, a situação é delicada. Em geral, essas superfícies não têm sido, de fato, restauradas, mas apenas limpas, reparadas e depois pintadas, ademais com tintas à base de polímeros, resultando em excessiva homogeneização do conjunto, desprezando-se a conservação das marcas deixadas pelo tempo e a própria superfície e suas técnicas de execução, que são também documento histórico. Além disso, arrisca-se a comprometer a sobrevida desses documentos com essas pinturas, pois, por não serem devidamente permeáveis, podem resultar em deterioração acelerada da matéria original dos substratos, caso as argamassas originais sejam à base de cal. Deve-se ainda lembrar que muitas dessas massas eram executadas inserindo-se também partes de pó de granito, mármore, mica, entre outros, resultando em massas que possuíam uma particular coloração e um peculiar modo de se comportar sob a luz, com discreta cintilação; o fato de pintá-las pode, portanto, resultar em graves problemas técnicos e estéticos. Até mesmo o tratamento de superfícies aparentes de tijolos tem deixado a desejar, tanto nos aspectos histórico-críticos quanto nos aspectos técnicos de execução. Recorre-se muito freqüentemente a limpezas profundas, substituições maciças e pinturas, sem se considerar de forma adequada os processos de limpeza sutis, que preservam a pátina e a consolidação do existente.

Deve-se lembrar que por meio de repintes, substituições e refazimentos maciços, insere-se ex novo uma dada obra em seu ambiente, ou seja, opera-se por meio de rupturas, quando o que mais interessa, do ponto de vista da preservação, é trabalhar com permanências, continuidades. $\bigcirc$ tratamento das superfícies deve, pois, ser encarado como um legítimo problema de restauração, isto é, como um ato histórico-crítico. Trata-se não apenas de "pele", de um órgão de primordial importância, mas também de local-testemunho da passagem da história, que não pode ser dissociado do restauro arquitetônico como um todo, não se resumindo a uma simples roupagem, nem a projeto de embalagens e, portanto, passível de ser mudado ao bel-prazer. Corre-se o risco de, ao não se levar em conta a consistência física, a estrutura formal do organismo arquitetônico em sua inteireza e seu transcorrer na história, comprometer a sua leitura.

\section{REFERÊNCIAS}

ASHURST, J; ASHURST, N. Practical Building Conservation. Hants: Gower, 1989. 5 v.

BALDINI, U. Teoria del restauro e unità di metodologia. Firenze: Nardini, 1997. 2 v.

BOITO, C. Questioni pratiche delle belle arti. Restauri, concorsi, legislazione, professione, insegnamento. Milano: Hoepli, 1893.

.Os restauradores. Tradução por P. e B. M. Kühl. Cotia: Ateliê, 2002. 
BRANDI, C. Il restauro. Teoria e pratica. Roma: Editori Riunite, 1994.

.Teoria da restauração.Tradução por Beatriz M. Kühl. Cotia: Ateliê, 2004.

CARBONARA, G. Avvicinamento al restauro. Napoli: Liguori, 1997.

CARBONARA, G.; CURUNI, S.A. (Orgs.). Intervista a Renato Bonelli. Tema, Torino, n. 3, p. 38-47, 1998.

CARTA de Veneza. Revista do patrimônio histórico e artístico nacional. Rio de Janeiro, n. 22, p. $106,1987$.

CHOAY, F. A alegoria do patrimônio. Tradução por Luciano Vieira Machado. São Paulo: Unesp/Estação Liberdade, 2001.

D'AVILER, A. C. Cours d'architecture qui comprend les ordres de Vignole. Paris: Mariette, 1710. 2 v.

DETRY, N.; PRUNET, P. Architecture et restauration. Sens et évolution d'une recherche. Paris: Les Éditions de la Passion, 2000.

FEILDEN, B. Conservation of Historic Buildings. Oxford: Butterworth, 2003.

FIORANI, D. (Org.). Il colore dell'edilizia storica. Roma: Gangemi, 2000.

GIOVANNONI, G. Vecchie Città: Edilizia Nuova. Vecchie città ed edilizia nuova. Torino: Utet, 1931.

Questioni di architettura nella storia e nella vita. Roma: Società d'Arte Ilustrata, 1925.

Verbete: Restauro dei Monumenti. In: ENCICLOPEDIA ITALIANA DI SCIENZE, LETTERE

ED ARTI. Roma: Istituto della Enciclopedia Italiana (Treccani), 1936, v. 18, p. 127-130.

JOKILEHTO, J. A bistory of architectural conservation. Oxford: Butterworth, 1999.

LA REGINA, F. Come un ferro rovente, cultura e prassi del restauro architettonico. Napoli: Clean, 1992.

MARCONI, P. Materia e significato. Roma: Laterza, 1999.

Dal piccolo al grande restauro. Venezia: Marsilio, 1988.

MIARELLI MARIANI, G. Coloriture urbane: omologazioni fra uniformità e dissonanze.Ananke, Firenze, n. 10, p. 10-23, 1995.

.I restauri di Pierre Prunet: un pretesto per parlare di architettura. Palladio, Roma, n. 27. p. 65-92, 2000 .

MORA, P; MORA, L. Le superfici architettoniche, materiale e colore. Bollettino d'arte, supplemento al n. 6, p. 17-24, 1984 .

MORRIS, W. Collected Works. Londres: s. n., 1915.

Annals of Museu Paulista.v. 12.Jan.-Dec. 2004. 
OLIVEIRA, M. M. de. Tecnologia da conservação e da restauração. Salvador: UFBA, 1995.

PANE, R. Attualitá e dialettica del restauro. Chieti, s. n., 1987.

PETRELLA,A. John Ruskin e l'economia politica dell'arte. Restauro, Napoli, v. 16, n. 91-92, p. 7-88, 1987.

PHILIPPOT, P. La notion de patine et le nettoyage des peintures. Bulletin de l'Institut Royale du Patrimoine Historique, Bruxelles, v. 9, p. 138-143, 1966.

PHILIPPOT, P.; MORA, L.; MORA, P. Il restauro degli intonaci colorati in architettura: L'Esempio di Roma e la Questione di Metodo. Bollettino d'arte, supplemento al n. 35-36, p. 139-141, 1986.

QUATREMÈRE DE QUINCY. Considérations morales sur la destination des ouvrages de l'art. Paris: Fayard, 1989.

Lettres à Miranda (1796). Paris: Macula, 1989.

.Restauração, restaurar, restituição e ruínas. Rotunda, Campinas, n. 2, p. 107-117, 2003.

RIEGL, A. Le culte moderne des monuments. Son essence et sa genèse. Tradução do alemão por Daniel Wieczorek. Paris: Seuil, 1984.

RUSKIN, J. The Seven Lamps of Architecture. 6 ed. Sunnyside: George Allen, 1889.

SCARROCCHIA, S. Alois Riegl: teoria e prassi della conservazione dei monumenti. Bologna: Accademia Clementina di Bologna, 1995.

TOLEDO, B. L. de. Patrimônio cultural: graus de intervenção nos monumentos históricos. Sinopses, São Paulo, n. 35, p. 32-38, 2001.

TORSELLO, B. P. La materia del restauro. Venezia: Marsilio, 1988.

VIOLLET-LE-DUC, E. E. Dictionnaire raisonné de l'architecture française du XI au XVI siècle. Paris: Libreries-Imprimeries Réunies, s.d., $10 \mathrm{v}$.

Entretiens sur l'architecture. Paris: Morel, 1863-1872. 2 v. Restauração.Tradução por B. M. Kühl. Cotia: Ateliê, 2001.

YOURCENAR, M. Le temps, ce grand sculpteur. Paris: Gallimard, 1983, p. 61-62.

Artigo apresentado em 07/2004. Aprovado em 10/2004. 